\title{
Demonstrating RoI in the Library: The Holy Grail Search Continues
}

\author{
Peter Edward Sidorko \\ Deputy University Librarian \\ The University of Hong Kong \\ peters@hku.hk
}

\begin{abstract}
Article type: Viewpoint.

Purpose: This article examines approaches by academic libraries in demonstrating return on investment (RoI).

Design/Methodology/Approach: As a participant in a recent international RoI study, the author reviews the various difficulties in developing a suitable methodology.
\end{abstract}

Findings: Using grant income as the basis for demonstrating RoI, it was found that wide differences in results may be attributable to a number of factors related to the parent organization, the availability of grant funding and the country of the study.

Research limitations/implications: Further work is necessary to arrive at a suitable methodology for a diverse range of academic libraries.

Practical implications: Library managers are alerted to issues and problems surrounding the development of return on investment methodologies.

Originality/value of paper: This paper will prove useful to librarians considering investing time and other resources in developing methodologies for demonstrating return on investment.

Keywords: Academic libraries, return on investment, library value. 
Holy Grail: A difficult or near-impossible goal that would prove to be a major benefit ... (Wiktionary, 2009)

\section{Tough times, tough measures}

"Frankly, funding needs to flow into other aspects of the academic program" (Kolowich, 2009: citing Daniel Greenstein, Vice Provost for Academic Planning and Programs at the University of California System). Current budget predictions for libraries do not present a positive picture. While the year 2009 saw the biggest global recession since the 1930's, the impact of this recession on libraries is expected to be less than one might well imagine. A recent global telephone survey at 495 libraries has produced a result that indicates that materials budgets are predicted to drop by 1.2\% (GfK NOP Market Research, 2009: 2) and overall library budgets set to decrease by $0.9 \%$ (ibid: 3 ).

Notwithstanding the seemingly small decline, the effect of such a reduction is of course greater than the $1.2 \%$ might suggest, yet what measures will librarians adopt in order to alleviate the effect of this reduction? In the same telephone survey, librarians identified ways in which they would deal with the recession. Three broad categories were identified, being “a) Acquiring additional funds, b) Demonstrating the value of library to stakeholders, and c) introducing cost controls” (ibid: 7). Interestingly, overall less than $20 \%$ of respondents identified "demonstrating the value of the library to stakeholders in order to combat recession” (ibid) as a strategy they would likely adopt. Academic librarians are the most likely group to introduce “cost controls” (85\%) as well as finding additional funds (40\%) but they rank the "value" card as the lowest.

It is perhaps not so surprising that demonstrating the value of the library to stakeholders is ranked as the least likely strategy to be adopted. The reasoning behind this reluctance is most likely related to one or more of three fundamental concerns: (i) there is great complexity in making such a successful demonstration; (ii) the expected rate of success is too low; and, (iii) there is no proven mechanism or formula that can be readily adopted. Yet during stringent economic times when competition for shrinking budgets is increasingly vigorous, libraries must work harder in addressing these 3 concerns otherwise the belief that "funding needs to flow into other aspects of the academic program” (Kolowich, 2009) will reign. With a view to at least partially addressing the latter of these three, a number of RoI studies for libraries have been undertaken in recent years. 
Of course the global economic crisis is not singularly to blame for reductions in library funding. Adverse perceptions that extend beyond the need to prioritise funding to more important programs have been with us for some time. The high profile case of the University of Wales, Bangor (UWB) sent a rush of outrage from librarians across the globe. A consultation document recommended a dramatic downsizing of library staff that focused on reducing 6 of the 7 existing subject librarian positions and eliminating 3 section heads which comprised a whole tier of management. The justification for this approach was based on the fact that "the support...from the qualified subject librarians is hard to justify in value-for-money terms (emphasis added) at a time when the process of literature searches is substantially de-skilled by online bibliographical resources” (Wright, 2007). Such perceptions are of course not isolated, and while the end result at Bangor was less drastic as first proposed, there is a salient message for all librarians to continuously highlight the value that their libraries bring to their parent organisations.

\section{Past studies}

Ever the resourceful optimists, librarians have strived to establish formulae/protocols/mechanisms/methodologies etc for demonstrating to stakeholders the value that a library provides to its constituents. One such approach has been to adopt a return on investment (RoI) methodology that can be used to clearly explain to administrators, in terms that they understand and indeed appreciate, the monetary value that they receive from their investment in library resources, services and facilities. In other words, for every dollar invested in the library, the library generates $x$ dollars in return. When $x>1$, a positive return is demonstrated. This seemingly simple approach has had only limited success in being applied for the reasons I have already stated. In 2008, Elsevier published its White Paper University investment in the library: What's the return? A case study at the University of Illinois at Urbana-Champaign (UIUC) (Luther, 2008). This in itself was a ground-breaking work that, for the first time, sought to establish a link between library resources and successful grant applications by faculty. This report also provides a useful analysis of earlier studies into cost/benefit analyses of libraries but as the report noted "there were no models for calculating a return on investment (ROI) in academic libraries” (Luther, 2008: 3) and in that sense it is even more ground-breaking.

Among the reports examined was the substantial Americans for Libraries Council's Worth Their Weight: An assessment of the evolving field of library valuation (Imholz \& Arns, 2007) which in itself provided an array of methodologies, albeit targeted at public libraries. Many of the methodologies in this report yielded a \$3 to \$6 RoI for 
every \$1 invested in those libraries. While notably US-centric, the Elsevier White Paper did not include reference to the British Library's Measuring our Value (British Library, 2003a) which forms part of the Library's broader strategy Increasing our Value (British Library, 2003). The methodology adopted in this report was the Contingent Valuation method, a quantitative methodology used by the UK Government, the World Bank and the OECD and supported by Nobel Prize winning economists Kenneth Arrow and Robert Solow. It was found that for every $£ 1$ of public funding the British Library receives annually, $£ 4.40$ is generated for the UK economy and that If the British Library did not exist, the UK would lose $£ 280 \mathrm{~m}$ of economic value per annum (ibid).

\section{The UIUC study (Phase I)}

The Elsevier White Paper was the culmination of a research project which germinated in 2006 and comprised a team that included input from publishers, librarians, researchers and economists. The study attempted to quantify the return on the investments that the University of Illinois at Urbana-Champaign (UIUC) had placed in its library with a particular focus on the library's role in securing grants in the externally funded research process. While the methodology is quite complex, put simply the hypothesis was that a certain percentage of faculty use citations from the library to help them with their grant applications and faculty believe that doing this is, to varying degrees, important in the process. Coupled with other factors such as grant proposal success rate, average grant income, number of grants expended and the value of the library materials budget, a formula was devised to provide a dollar figure in grant income for each $\$ 1$ invested in library resources (RoI). For the UIUC the RoI was found to be $\$ 4.38$, in other words for every $\$ 1$ the University invested in the library, \$4.38 in grant income was generated. This figure bears a striking resemblance to the British Library’s £4.40, even though different approaches were adopted and the UIUC study was limited to only one aspect, namely grant success.

While the study and its outcomes are well documented in the White Paper itself as well as elsewhere (Kaufman, 2008, 2008a; Kaufman \& Watstein, 2008), and so will not be a focus here, it is important to note from the study that it was "limited to grant income and does not address the value of resources to faculty in conducting their research or teaching" (Luther, 2008: 4) or for that matter the value of the library to students in their learning or to the community in terms of knowledge exchange, and so on. This in itself is no criticism of the study but does serve to highlight the complexity of the environment in which academic libraries exist and by extension the difficulty they face in providing any comprehensive RoI. 


\section{The International study (Phase II)}

In the Elsevier White Paper (Luther, 2008) it was noted that "It would be interesting to replicate the survey at other universities to determine if the factors incorporated into the model vary, and to identify the ROI for a range of institutions” (ibid: 4). Phase 2 of the study attempted just that. Phase II of the study expanded the methodology to eight institutions in eight countries in order to assess the applicability of the Phase I methodology to academic libraries globally. Libraries were recruited from Africa, Asia, Oceania, North America and Western Europe. The study once again adopted a triangulated approach but with a minor revision to the RoI formula used in Phase 1. The methodology and formula was constructed around: (i) a survey of faculty members; (ii) data collection (covering a 10 year span), and; (iii) interviews with senior faculty and administrators. Essentially, in perhaps over-simplistic terms, the formula adopted was: (grant funding received with the library's help) divided by (the library budget). The full formula used for the eight libraries in the study is reproduced below.

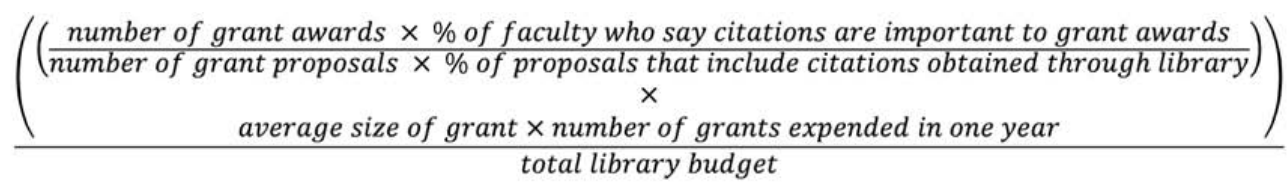

Formula used to measure library RoI in grants

While the Elsevier White Paper into Phase II is still in draft form (Tenopir, et. al, 2010), it can be noted that the tentative results for the eight institutions and the new calculation, using the revised formula, for the UIUC Library are depicted in the following table.

\begin{tabular}{|l|l|l|l|l|l|l|l|l|l||}
\hline University & $\begin{array}{l}\text { Univ. } \\
1\end{array}$ & $\begin{array}{l}\text { Univ. } \\
2\end{array}$ & $\begin{array}{l}\text { Univ. } \\
3\end{array}$ & $\begin{array}{l}\text { Univ. } \\
4\end{array}$ & $\begin{array}{l}\text { Univ. } \\
5\end{array}$ & $\begin{array}{l}\text { Univ. } \\
6\end{array}$ & $\begin{array}{l}\text { Univ. } \\
7\end{array}$ & $\begin{array}{l}\text { Univ. } \\
8\end{array}$ & UIUC \\
\hline RoI Value & 3.44 & 15.54 & 0.27 & 13.16 & 0.27 & 1.31 & 0.64 & 1.43 & 5.60 \\
\hline
\end{tabular}

International Study (Phase II) RoI Values.

As can be seen from the table a wide range of RoI was estimated through the study and they varied from 0.27 through to 15.54. In other words, for each unit of currency invested in the library, 0.27 to 15.54 times that unit was generated in grant 
income. The returns for three of the eight institutions were below 1, in other words those three generated a negative return in terms of contributing to grant income. While some variance was expected, the extent of this appears considerably more significant than was originally anticipated with the contrast clearly discernible in the following graph.

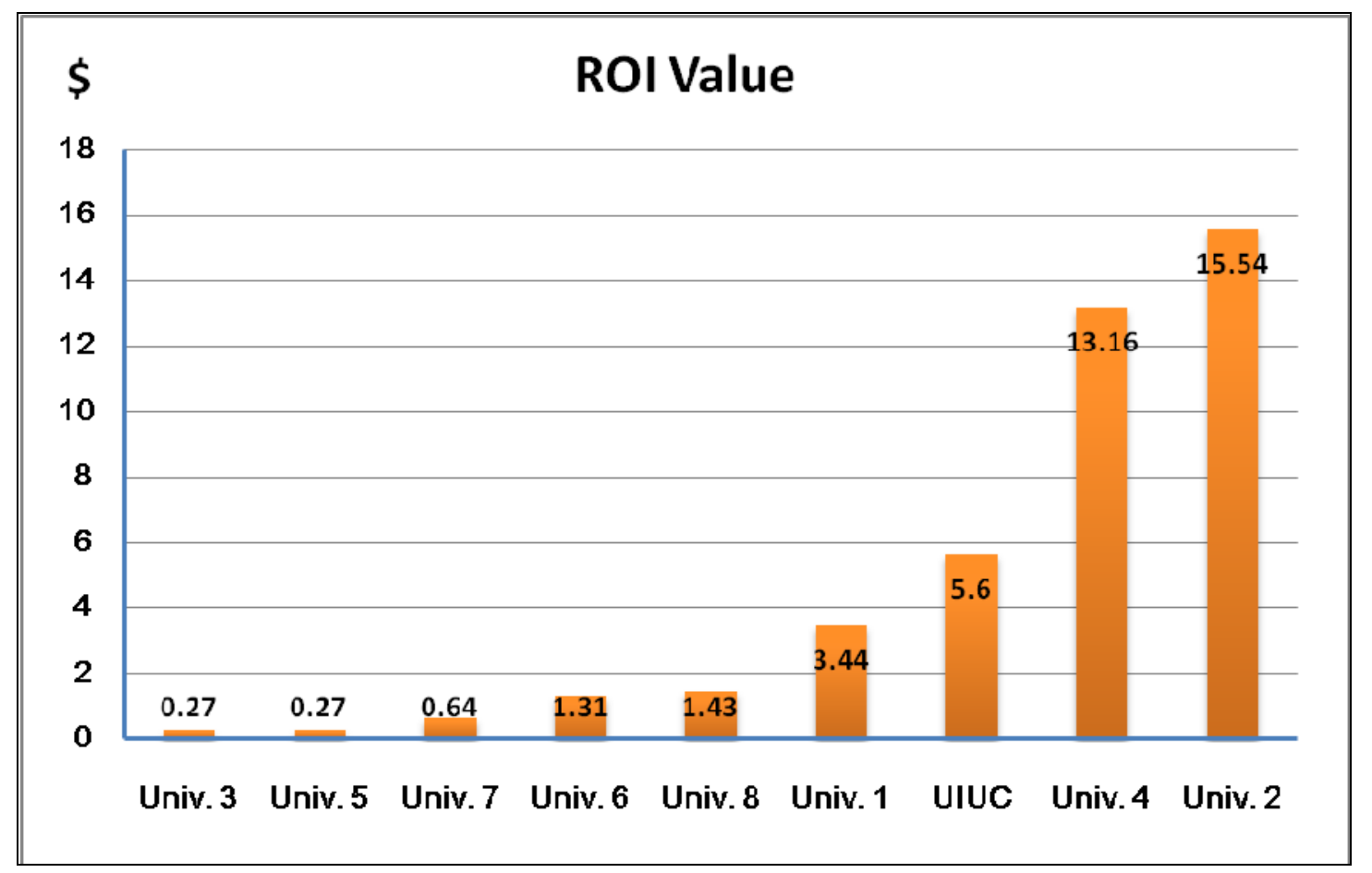

RoI of the eight institutions showing three below the $\$ 1$ mark

Without detailed knowledge of the eight institutions it remains nearly impossible to account for the degree of variance. It may be that some or all of the following factors/variables contributed to this.

\section{The Predominating mission of the institution.}

Perhaps most obvious among the variables that would contribute to the significant variance is the degree to which each institution is research-focused. Institutions' whose primary mission is teaching excellence, are less inclined to apply for grants and in most cases have less opportunity and access to large grants for teaching and learning based research and development. By contrast institutions with a heavy research focus will be more aggressive in their pursuit of grants and generally have a wider range of grants available for which they may apply.

2. The Discipline emphasis of the institution. 
The availability of grants is even more readily accessible to those organizations whose research emphasis is in the science/technology/medicine (STM) fields compared to those whose emphasis is on social sciences and humanities. Additional to this is the general recognition that STM disciplines, and in particular the life sciences, tend to draw larger grants.

\section{The National agenda and availability of external funding sources.}

Across eight countries it may be well expected that the extent to which external funding sources will be available will vary significantly. In some countries, academic institutions rely more on government funding than competitive grant funding than they do in other countries.

\section{Unrepresentative faculty data.}

While only a small part of the RoI formula is based on the survey results, results may have been skewed if unrepresentative responses were solicited from faculty. In other words if the percentage of responses from each faculty does not align with the percentage of the total faculty population that faculty represents, the results are not representative. The effect of this will vary depending on the degree to which that discipline is heavily successful with grants or not. That is to say it may have had a positive or an adverse affect on the RoI outcome. To illustrate this point, at University 5 the Life Sciences, Health and Medicine faculty account for $64.2 \%$ of the total institution's faculty whereas only $28.8 \%$ of the survey responses came from that faculty, most likely leading to a lower RoI given that these disciplines are often highly successful with large grant applications.

\section{Other difficulties and possible limitations.}

There are many other possibilities that may have contributed to the discrepancies. Most of these primarily relate to the data collection processes. For example, the issue of grant funding may be seen as sensitive by some institutions' administrations who may have consequently been reluctant to disclose the data, making the investigation process not only time consuming but, more importantly, prone to error and omission. Even for those institutions that may not have encountered such reluctance of disclosure there were most likely variations in data that the eight universities kept and variations in the depth of the data kept, bearing in mind that 10 years of data was required as the study period.

Other factors that certainly contributed to complexity in the data gathering process, and thereby may have contributed to the variance include: 
- Differences in terminology (e.g. different academic ranks and how those translated in the data);

- The variations in data collection periods (e.g. the use of fiscal year, academic year, calendar year);

- Languages;

- The complexity of managing eight different datasets of varying quality and volume.

At the time of writing, further analysis of data is being undertaken by the project group in order to ensure that the data collected is accurate and that the findings are sound. This is an essential process if any validity is to be drawn from the results and if they are to be used persuasively for library support, be that financial or other.

\section{Further findings from the international study}

While the "silver bullet" of a singular RoI figure may be persuasive with administrators governing libraries, the purpose of the Phase II study was not limited to establishing this single figure for the eight institutions. The complexity of the study through its triangulated approach yielded a wealth of other data that, while in part contributing to the RoI formula, also leads to revealing several key findings and conclusions. The draft White Paper (Tenopir et. al., 2010: 22) of the study also demonstrates how the libraries contributed to administrator's long term goals in terms of "raising the university's prestige, attracting and retaining productive faculty, and fostering innovative research and interdisciplinary collaboration” (ibid). Specifically, it concludes that:

- Use of library. Library resources are used by faculty in support of their scholarship, research, and teaching. Respondents reported that they spent at least 3.5 hours per week finding and accessing articles, and at least 9.8 hours reading articles;

- E-resources. Faculty use e-resources extensively and find that these increase their research efficiency as well as increase their productivity and their interdisciplinary and international perspectives. Furthermore, it was found that most respondents access at least half of the articles and books they cite in grant proposals, reports, and publications from their institutional library e-resources;

- Administrator needs. From the interviews with administrators, the common themes of recruiting, retaining and evaluating productive faculty, undergraduate, and postgraduate students as well as the need for institutional 
international reputation were present. Administrators relied on the library to assist in these processes;

- Library resources and grant proposals. The vast majority of faculty use library resources to help prepare their grant proposals, articles, and reports and they consider these resources an important part of the grants process. Respondents cite an average of 14.93 to 26.5 books or articles in each grant proposal they write, 22.02 to 42.2 in each final grant report, and 22.1 to 42.19 for each article they write. For every article a respondent cites, s/he reads 18.0 to 40.22 other articles.

While most librarians would hardly find these conclusions surprising, they nonetheless serve to be reassuring and as acknowledgment of what we have long believed. And, given that these findings were highly consistent across all eight institutions, there is little scope in questioning their validity.

\section{The Next study (Phase III)}

While the results from Phase II are being further analysed and assessed for accuracy and error, plans are nonetheless afoot to extend the study to a third phase which will adopt a much broader approach aiming to examine mechanisms to quantify the contributions which the library makes in creating value in multiple ways, as opposed to Phases I and II which focused on grant income. Phase III will look at multiple measures to estimate the returns on investment the library makes in its "contributions to teaching, student engagement, and the university's overall stature” (Tenopir, et. al., 2010: 22). To make this more complex phase more manageable, a smaller number of institutions will be used as the test beds. It is proposed that three institutions from the United States will be used along with participation from the Association of Research Libraries (ARL) to develop tools that can be tested in other libraries. Given the difficulties evidenced in Phase II, this phase represents an even more complex attempt to derive a methodology from which all academic and research libraries serve to benefit.

\section{Conclusion}

These studies have provided a beginning step to an important way of thinking about academic libraries and their role in the institutions they serve. Irrespective of the type of library, the clientele they serve, the countries to which they belong, the ever increasing call for libraries to demonstrate the value that they bring to their constituents is a call that can no longer be ignored by academic librarians or rejected on the grounds of difficulty. Despite the difficulties and the investment required in 
developing these methodologies, the necessity to "get it right" must be at the forefront so that a rigorous protocol is developed that cannot be challenged or dismissed as faulted. While the complexity of the task remains a reality, studies such as those discussed above have served to highlight this growing need and to move some way towards developing a methodology, or more likely, methodologies, that can be adapted contextually to suit institutional individuality and idiosyncrasy. Like the search for the mythical holy grail, the journey is long. Unlike the search for the mythical holy grail, the journey will have an end. 


\section{References}

British Library (2003), Increasing our Value (December 2003).

URL: http://www.bl.uk/aboutus/stratpolprog/increasingvalue/ [22 January, 2010].

British Library (2003a), Measuring our Value: Results of an Independent Economic Impact Study Commissioned by the British Library to Measure the Library's Direct and Indirect Value to the UK Economy (December 2003).

URL: $\quad$ http://www.bl.uk/aboutus/stratpolprog/increasingvalue/measuring.pdf January, 2010].

GfK NOP Market Research (2009), Library Budget Predictions for 2010: Results from a Telephone Survey, August, 2009. (Unpublished document).

Imholz, S., \& Arns, J.W. (2007), Worth Their Weight: An Assessment of the Evolving Field of Library Valuation. Americans for Libraries Council.

URL: http://www.actforlibraries.org/pdf/WorthTheirWeight.pdf [22 January, 2010].

Kaufman, P. (2008), “The Library as strategic investment: Results of the Illinois return on investment study”, LIBER Quarterly, 18(3/4), 424-436.

Kaufman, P. (2008a), "University investments in the library: What's the payback? A Case study at the University of Illinois at Urbana-Champaign”, ALA Midwinter 2008, Philadelphia, 2008. URL: http://www.ideals.uiuc.edu/handle/2142/3587 [29 January, 2010].

Kaufman, P \& Watstein, S.B. (2008), “Library value (return on investment, ROI) and the challenge of placing a value on public services”, Reference Services Review, 36(3), 226-231.

Kolowich, S. (2009), “Libraries of the future, Inside Higher Ed”, September 24, 2009. URL: http://www.insidehighered.com/news/2009/09/24/libraries [22 January, 2010].

Luther, J. (2008), University Investment in the Library: What's the Return? A Case Study at the University of Illinois at Urbana-Champaign. Report prepared for Elsevier Library Connect.

URL: http://libraryconnect.elsevier.com/whitepapers/0108/lcwp010801.html [22 January, 2010]. 
Tenopir, C, et. al. (2010), University Investment in the Library, Phase II: An International Study of the Library's Value to the Grants Process. Unpublished Draft Report prepared for Elsevier Library Connect.

Wright, J. (2007), "From adversity comes strength? Raising a new profile for the Library at the University of Wales, Bangor”, Irish National and University Library Staff Conference, National University of Ireland, Galway June 14-16, 2007. URL: http://www.conference.ie/Conferences/menu.asp?menu=245\&Conference $=36$ $[29$ January, 2010].

Wiktionary (2009), Holy Grail. URL: en.wiktionary.org/wiki/Holy_Grail [29January, 2010]. 